\title{
Sociobiology
}

RESEARCH ARTICLE - ANTS

\section{Necrophilous Ants (Hymenoptera: Formicidae) in Diverse Habitats in Taiwan}

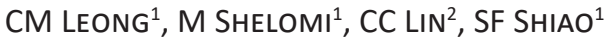 \\ 1 - Department of Entomology, National Taiwan University, Taipei, Taiwan \\ 2 - Department of Biology, National Changhua University of Education, Changhua, Taiwan
}

\section{Article History \\ Edited by \\ Evandro N. Silva, UEFS, Brazil \\ Received 22 May 2018 \\ Initial acceptance 21 July 2018 \\ Final acceptance 10 December 2018 \\ Publication date 20 August 2019}

\section{Keywords}

Forensic entomology, ants, checklist, decomposition.

\section{Corresponding author}

Chi-Man Leong

Department of Entomology

National Taiwan University

No. 1, Roosevelt Road, Section 4

Taipei, 106 Taiwan

E-Mail: chimanleo@gmail.com

\begin{abstract}
Ants are a highly diverse group that not only are often strongly associated with certain habitat types, but also can be found on carcasses and, therefore, in crime scenes. In the present study, a survey of the necrophilous ants in Taiwan was conducted and a preliminary species checklist was provided for the first time. The aim of this study was primarily to offer information on Taiwanese ant species of forensic significance. A total of 50 ant species/morphospecies from 26 genera were collected from large scale regions in Taiwan using combination pig liver bait and pitfall traps, bringing the Taiwanese necrophilous ants up to 55 species from 33 genera within the known Taiwanese ant fauna of 288 species from 71 genera. Seventeen species found in this study are tramp or potentially exotic species, which often dominated the baits. Use of pitfall traps increased the diversity of ants collected relative to hand-collecting from the carcass, adding useful data. These necrophilous ants may play important roles in carcass decomposition and can be useful in reconstructing crime scenes, as certain ants are more common in certain habitat types. This checklist and accompanying habitat information of these ants is likely the first such comprehensive data in Taiwan applying ants to the field of forensic entomology.
\end{abstract}

\section{Introduction}

Forensic entomology is, in part, the study of the arthropods related to the decomposition of carcasses. Studies in the field can aid in reconstructing the decomposition process of the carcass, with significance for medicolegal investigations (Amendt et al., 2004). For example, minimum postmortem interval (mPMI), representing the minimum period of time elapsed since death, can be estimated by using the life history data of blow fly larvae (Calliphoridae), and the community of arthropod succession can be used to estimate the stages of carcass decomposition (VanLaerhoven, 2008). In addition, as arthropod faunas differ within different types of habitats, they can provide clues to the location of a crime (Silahuddin et al., 2015). However, the flies of greatest forensic significance (such as Calliphoridae) are cosmopolitan and not good identifiers of any particular habitat and season (Wells, 1991; Santos et al., 2014). By contrast, ants (Formicidae) not only form different functional groups that reliably identify different types of habitats (Hölldobler \& Wilson, 1990; Andersen et al., 2002), but also are easily found on carcasses in different succession stages (e.g. Carvalho et al., 2004; Paula et al., 2016). Moreover, Paula et al. (2016) found that ants may indicate different weather patterns within the same region. Thus, ants may provide useful clues for forensic investigations.

Most ant studies within forensic entomology focused on the relationship between ants and flies. Ants can cause an overestimate of PMI due to their preying on maggots and therefore decreasing the decomposition rate (e.g.Wells \& Greenberg, 1994). The burying behavior of imported fire ants was found to cause wounds in human corpses, which will further decrease decomposition time (Lindgren et al., 2011). However, a recent study observed an ant species, Pheidole 
radoszkowskii Mayr, feeding directly on carcasses. This observation differed from previous studies that assumed that ants mainly fed on fly eggs and maggots (Sales et al., 2016). Another case demonstrated that data from the developmental stages of alate queen pupae of Anoplolepis gracilipes Smith in a colony found next to human remains correctly estimated PMI (Goff \& Win, 1997).

Although PMI estimation is the most important subject in forensic entomology, the ants can also serve as indicators for microhabitats (Andersen et al., 2002; Del Toroet al., 2012) and as causes of postmortem injury, making special marks on the skin of the body (e.g. Campobasso et al., 2009; Bonacci \& Vercillo, 2015).

This potential of ants has long been overlooked in forensic entomology, where past surveys of insect succession on carcasses or crime studies usually did not provide specieslevel identification for ants (Carvalho et al., 2004; Moura et al., 2005; Bonacci et al., 2010; Bonacci et al., 2011). Until now, only a few forensic entomology studies in Portugal, Brazil and Taiwan recorded ant species (Hwang, 2011; Castro et al., 2014; Andrade-Silva et al., 2015; Paula et al., 2016). Only one survey, Hwang (2011), focused specifically on necrophilous ants, surveying the Nanrenshan and Fushan research forests in Taiwan. This data is thus limited to the species present in the habitat type of primary forest. To further increase our knowledge of ants in forensic entomology, especially of Taiwan, we performed a survey of different regions and habitats in Taiwan. We found a diverse set of ant species and genera trapped by pig liver, and describe our findings here along with a preliminary checklist of necrophilous ants from Taiwan.

\section{Materials and Methods}

Usually in surveys of insect fauna on carcasses, the bait materials of rat or pig carcass are used. We used a different material, pig liver, as bait due to its strong odor and easy preparation in trapping. However, liver desiccates more easily than rat carcass, because the liver is without skin and hair to prevent evaporation. To compare the attractive capabilities between rat carcass and pig liver, we compared the trapped ant genera of this study with prior data (Hwang, 2011; Hwang, 2012) ( Fig 1) that used 20g rat carcass baits to trap necrophilous ants in mature forest habitats of Taiwan (Fushan, Yilan County; and Nanrenshan, Pingtung County). Because ant genera are considered stable in taxonomy (Ward, 2007), and can also represent the characteristics of collecting regions and micro-habitats (Guénard et al., 2010), genus level data were adopted as indicators in this study.

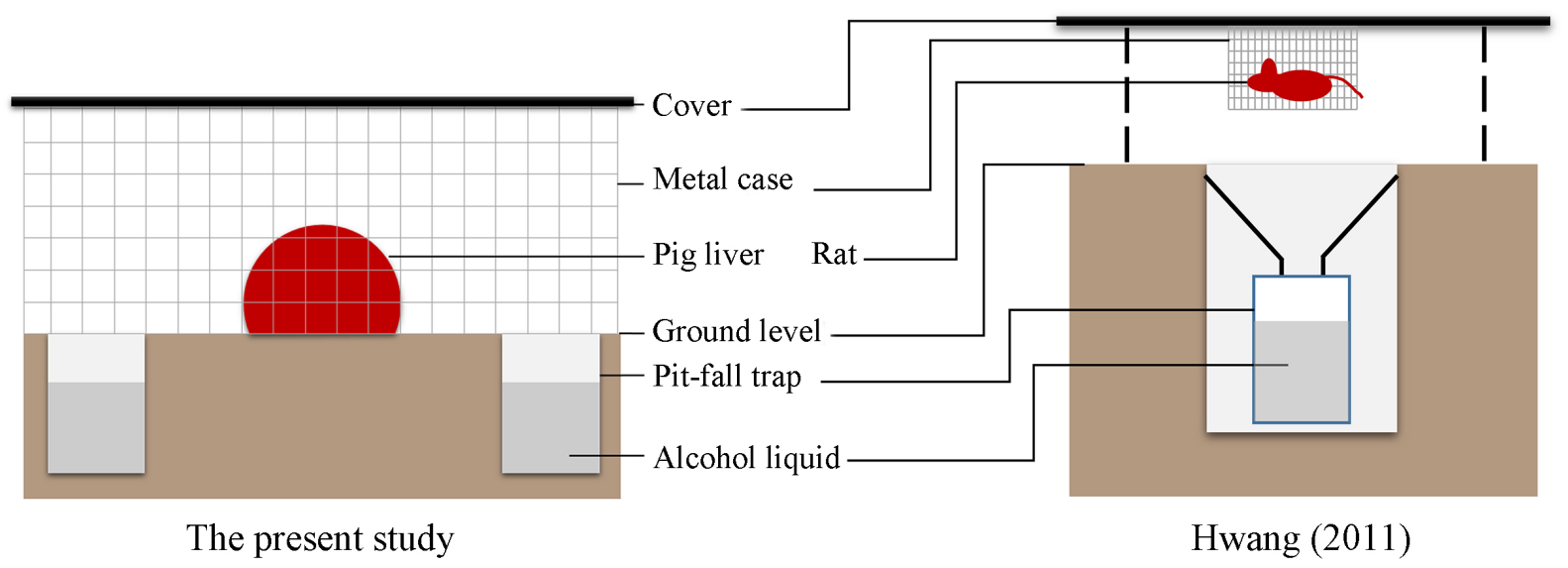

Fig 1. Left: Diagram of the trap for surveys in 2015 to 2016. Right: Redrawn diagram of the trap of Hwang (2011).

Our specimens were collected in the southern counties of Taiwan (Hualian, Taitung, Pingtung, Kaohsiung, Tainan, Chiayi, Nantou, Yunlin and Changhua Counties) in January 2011 and from February 2012 to July 2013, using the pig liver baited traps as in Lin and Shiao (2013), only set up above the ground rather than as pitfall traps within the ground. After Hwang (2011) reported that pitfall traps combined with baited traps most effectively collect necrophilous insects living in the soil or ground such as ants and beetles, we designed a new trap for collecting ants easily in our study. It is a cuboid cage $\left(26 \times 17 \times 13.5 \mathrm{~cm}^{3}\right)$ with a rectangular plastic cover $(35 \times 26$ $\left.\mathrm{cm}^{2}\right)$ combined with two cylindrical pitfall traps $\left(7 \times 3.2^{2} \times \pi\right.$ $\mathrm{cm}^{3}$ ) (Fig. 1). Here, $50 \mathrm{~g}$ fresh pig liver was placed in the center of cage, the pitfall traps filled two-thirds full of $75 \%$ ethanol, and trapped specimens collected after seven days. We used these traps to collect from Taipei County in the autumns of 2015 and 2016 (temperature: $23.5-27.8^{\circ} \mathrm{C}$, humidity: 75$78 \%$ in average across the months). Detailed collecting data, sites, and forest habitats are respectively shown in Table 1 and Figs. 2 and 3. All specimens were preserved in 75\% ethanol before being point-mounted for identification via stereomicroscope (Leica Z16 APO, Wetzlar, Germany).

For ant identification, we used a diagnostic key of Taiwanese ants (Terayama, 2009), also consulting a bibliographic database (antmaps.org, 2017), previously identified ant specimens from Taiwan (Social Insect Laboratory, National Changhua University of Education), and the type specimens on the database of Antweb.org (2017). 
Table 1. Collecting data in this study (including collecting code, GPS location, collector, and habitat type NF = Non-forest, $\mathrm{SF}=$ Secondary forest, $\mathrm{PF}=$ Primary forest).

\begin{tabular}{|c|c|c|c|c|c|}
\hline Code & Date & County/City & GPS $\left({ }^{\circ} \mathrm{N},{ }^{\circ} \mathrm{E}\right)$ & Collector & Habitat type \\
\hline TWFA01 & 11-Jul-2011 & Changhua & $23.8560,120.6198$ & S. W. Lin & $\mathrm{SF}$ \\
\hline TWFA02 & 12-Jul-2011 & Changhua & $23.8181,120.6211$ & S. W. Lin & $\mathrm{NF}$ \\
\hline TWFA03 & 13-Jul-2011 & Yunlin & $23.7919,120.6371$ & S. W. Lin & $\mathrm{SF}$ \\
\hline TWFA04 & 15-Jul-2011 & Nantou & $23.8315,120.6219$ & S. W. Lin & $\mathrm{SF}$ \\
\hline TWFA05 & 16-Jul-2011 & Tainan & $23.0716,120.5190$ & S. W. Lin & NF \\
\hline TWFA06 & 17-Jul-2011 & Tainan & $23.2904,120.5038$ & S. W. Lin & $\mathrm{PF}$ \\
\hline TWFA07 & 18-Jul-2011 & Kaohsiung & $23.0656,120.6197$ & S. W. Lin & $\mathrm{PF}$ \\
\hline TWFA08 & 19-Jul-2011 & Kaohsiung & $23.0066,120.6477$ & S. W. Lin & $\mathrm{NF}$ \\
\hline TWFA09 & 20-Jul-2011 & Pingtung & $22.6485,120.6285$ & S. W. Lin & $\mathrm{SF}$ \\
\hline TWFA10 & 21-Jul-2011 & Pingtung & $22.8647,120.6430$ & S. W. Lin & $\mathrm{NF}$ \\
\hline TWFA11 & 22-Jul-2011 & Pingtung & $22.5216,120.6167$ & S. W. Lin & $\mathrm{NF}$ \\
\hline TWFA12 & 23-Jul-2011 & Pingtung & $22.7758,120.6283$ & S. W. Lin & NF \\
\hline TWFA13 & 24-Jul-2011 & Pingtung & $22.1624,120.8235$ & S. W. Lin & $\mathrm{PF}$ \\
\hline TWFA14 & 25-Jul-2011 & Hualien & $23.5501,121.3891$ & S. W. Lin & NF \\
\hline TWFA15 & 26-Jul-2011 & Taitung & $22.7897,121.1592$ & S. W. Lin & NF \\
\hline TWFA16 & 11-Feb-2012 & Nantou & $23.5221,120.8399$ & Z. S. Wu & $\mathrm{PF}$ \\
\hline TWFA17 & 10-Aug-2012 & Nantou & $24.0234,121.1289$ & Z. S. Wu & $\mathrm{PF}$ \\
\hline TWFA18 & 11-Aug-2012 & Nantou & $24.0453,121.2743$ & Z. S. Wu & $\mathrm{PF}$ \\
\hline TWFA19 & 05-Oct-2012 & Nantou & $24.0934,121.0311$ & Z. S. Wu & $\mathrm{PF}$ \\
\hline TWFA20 & 30-Jul-2013 & Taitung & $22.0752,121.5066$ & Z. S. Wu & NF \\
\hline TWFA2 1 & 30-Jul-2013 & Taitung & $22.0803,121.5136$ & Z. S. Wu & $\mathrm{NF}$ \\
\hline TWFA22 & 06-Nov-2015 & Taipei & $25.0124,121.5476$ & C. M. Leong & NF \\
\hline TWFA23 & 19-Sep-2016 & Taipei & $25.0126,121.5470$ & C. M. Leong & $\mathrm{NF}$ \\
\hline TWFA24 & 26-Sep-2016 & Taipei & $25.0116,121.5444$ & C. M. Leong & NF \\
\hline TWFA25 & 30-Sep-2016 & Taipei & $25.0177,121.5524$ & C. M. Leong & NF \\
\hline TWFA26 & 05-Oct-2016 & Taipei & $25.0158,121.5575$ & C. M. Leong & $\mathrm{SF}$ \\
\hline TWFA27 & 12-Oct-2016 & Taipei & $25.0157,121.5561$ & C. M. Leong & $\mathrm{SF}$ \\
\hline TWFA28 & 19-Oct-2016 & Taipei & $25.0115,121.5448$ & C. M. Leong & NF \\
\hline TWFA29 & 26-Oct-2016 & Taipei & $25.0114,121.5453$ & C. M. Leong & $\mathrm{NF}$ \\
\hline
\end{tabular}

Any taxonomic changes and updates were incorporated into our results as per changes in the database AntCat.org (2017). All specimens were deposited in the Insect Systematics Lab., Department of Entomology, National Taiwan University (Taipei, Taiwan). In addition, we re-examined the voucher specimens of Hwang (2011), which are deposited in the Taiwan Forestry Research Institute (per. Comm. With Dr. Wenbe Hwang).

\section{Results}

In the present study, a total of 50 ant species/ morphospecies from 26 genera were collected as presented in Table 2, including 24 newly recorded necrophilous species of potential forensic impact in Taiwan, as well as Technomyrmex difficilis Forel, a new record for Taiwanese ant fauna (see Yamane et al., 2018). We also collected 21 tramp or potentially exotic species, which comprised a large proportion of our collected samples as shown in Table 2.

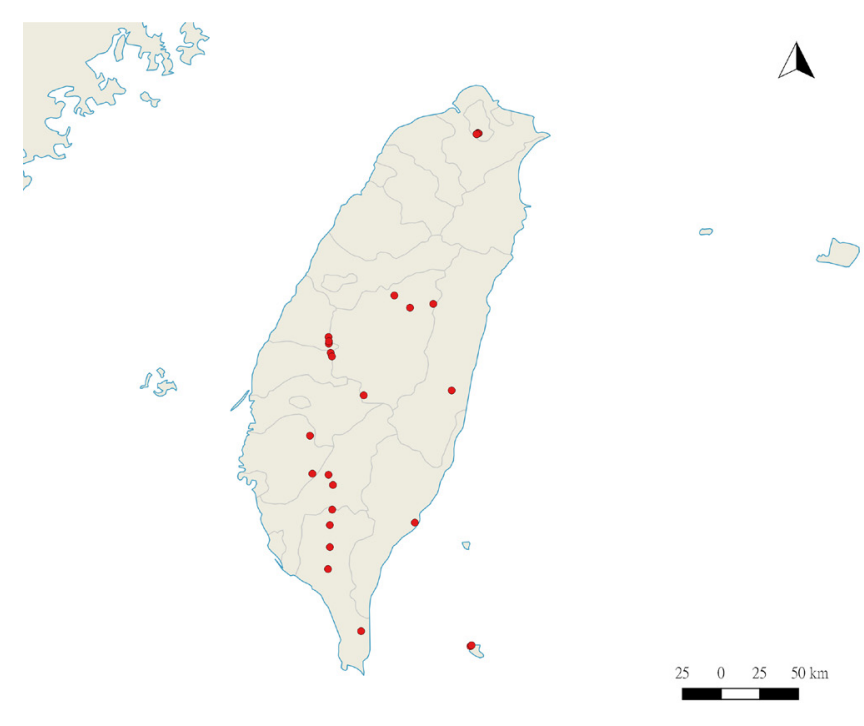

Fig 2. Collection sites of the surveys (red dots) for the necrophilous ants in Taiwan. 
Table 2. Taiwanese necrophilous ant species collected in the studies of Hwang in 2011 and the present study and their habitats. NF $=$ Nonforest, $\mathrm{SF}=$ Secondary forest, $\mathrm{PF}=$ Primary forest.

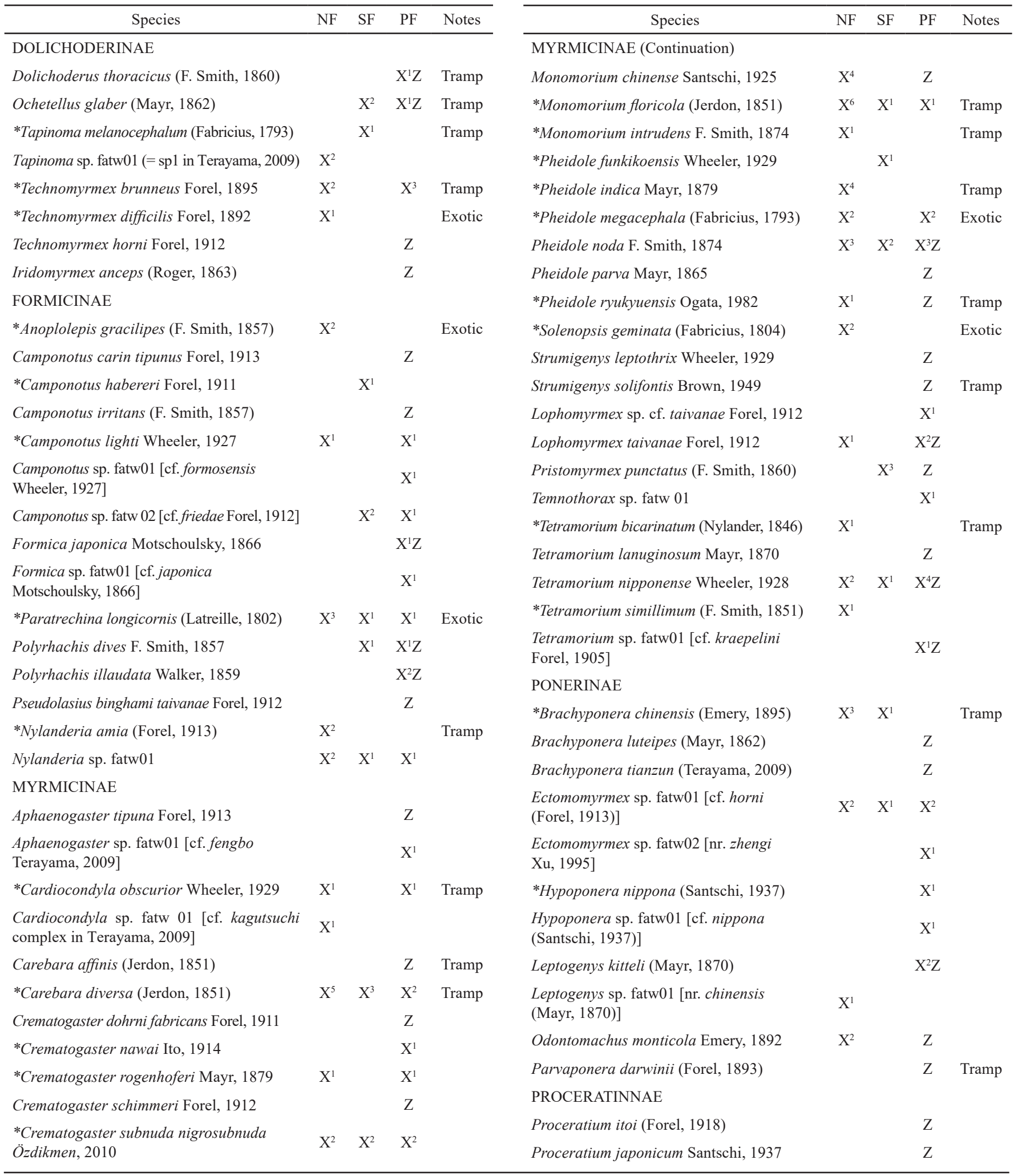

Asterisks $(*)$ indicate newly recorded species for necrophilous ants in Taiwan.

" $\mathrm{X}$ " : " $\mathrm{X}$ " represent that species was present in our study, "Y" meant how many times collected.

"Z": "Z" represent that species was present in Hwang's (2011) study.

Notes: tramp species are native for Taiwan, but spreading to different regions based on biogeography; exotic are non-native for Taiwan, and they easily spread to different regions. 
Regarding the necrophilous ant records of Hwang (2011), some taxonomic problems were revised based on the synopsis of Taiwanese ant fauna (Terayama, 2009) and our review of the voucher specimens of Hwang (2011). According to Terayama (2009), Ectomomyrmex javanus, Technomyrmex albipes and Euponera sharpi are not present in Taiwan. After examining the voucher specimens (Hwang, 2011), we speculate that Pseudoponera stigma could have been misidentified, because we did not find P. stigma among the voucher specimens and it is native to the Neotropics, so we provisionally excluded the record of $P$. stigma from this literature.

\section{TWFA25}

\section{Brachyponera chinensis} Monomorium floricola Monomorium intrudens Paratrechina amia Technomyrmex brunneus (occupy)

\section{TWFA23}

Crematogaster rogenhoferi Monomorium chinense Paratrechina longicornis Pheidole noda (occupy) Pheidole indica Tetramorium nipponense

\section{TWFA22}

Carabare diversa (occupy)

Brachyponera chinensis Monomorium chinense Monomorium floricola Paratrechina amia Pheidole noda Pheidole indica Pheidole ryukyuensis Tetramorium bicarinatum

\section{TWFA28}

Carabare diversa (occupy) Monomorium chinense Monomorium floricola Odontomachus monticola Paratrechina longicornis Pheidole indica Pheidole noda
TWFA26

Brachyponera chinensis

Ectomomyrmex sp. fatw01 [cf. horni]

Paratrechina longicornis

Pheidole noda (occupy)

Pristomyrmex punctatus

Tetramorium nipponense

\author{
TWFA27 \\ Carabare diversa (occupy) \\ Camponotus sp. fatw02 [cf. \\ friedae] \\ Pheidole funkikoensis \\ Pheidole noda \\ Pristomyrmex punctatus \\ Nylanderia sp. fatw01
}

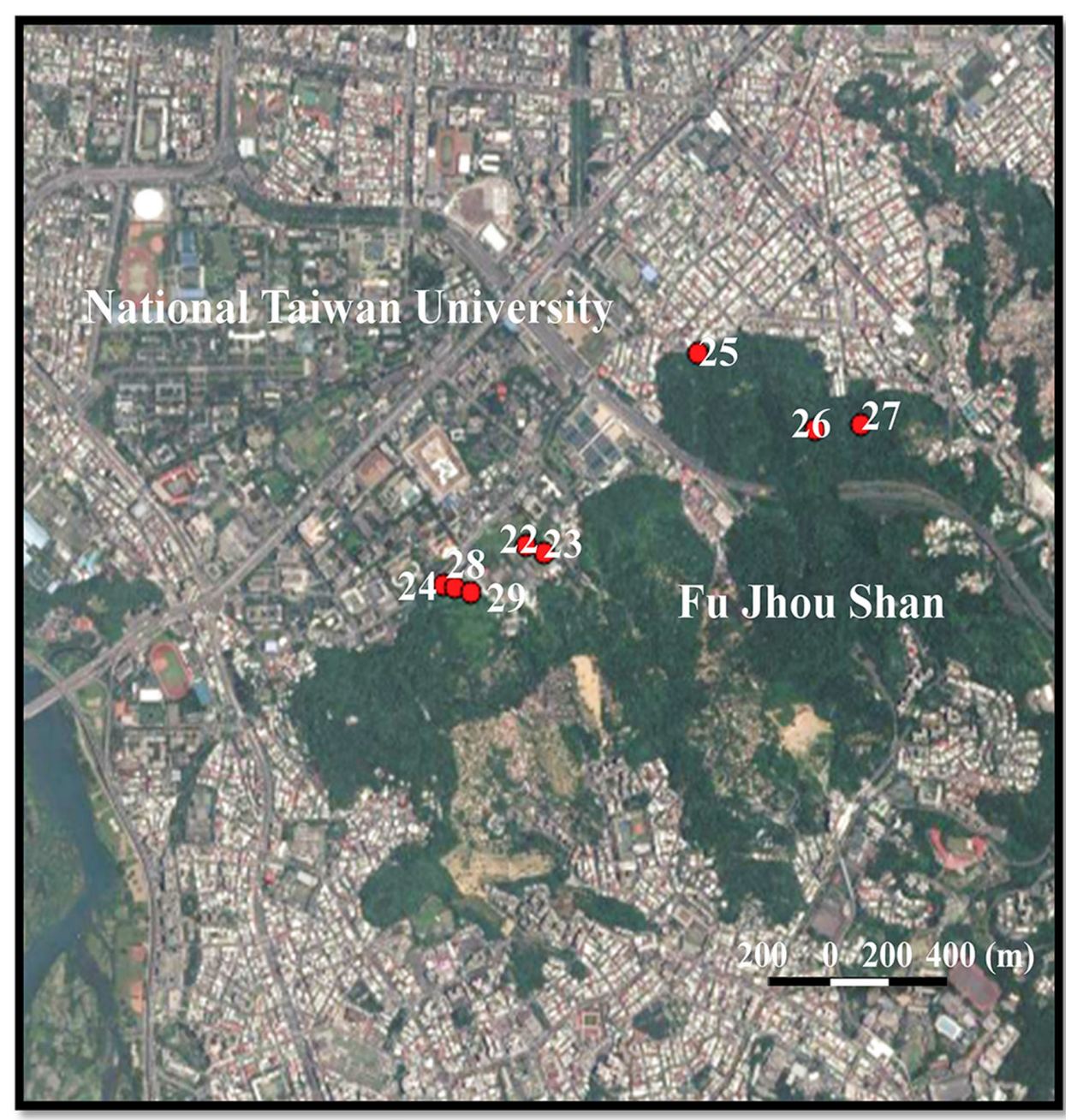

TWFA24

Odontomachus monticola

*Typhoon
TWFA29

Carabare diversa (occupy) Cardiocondyla obscurior Monomorium chinense Monomorium floricola Pheidole indica

Fig 3. A close-up of Taipei county; within Taipei (2015-2016 sampling), the observed ant species are listed with the dominant, resource-occupying ant species given in red. Note that collection of sample TWFA24 was hindered by inclement weather (modified from Google Map, 2017). 
To compare the different bait materials used to sample for necrophilous ants, we compared the genera collected in this study and those in Hwang (2011), which used rat carcasses to trap ants in mature forests. Although the ant species we collected in our pig liver traps are different from those of the rat carcass traps, the community of ant genera is mostly similar. Nineteen $(19 / 25=76 \%)$ from twenty-five genera are the same in Hwang's study, and six genera were only found in Hwang's study (Figure 4). However, three of these six genera are Strumigenys and Proceratium, which are thought to feed on springtails and spiders respectively (Hölldobler \& Wilson, 1990) and thus do not represent true necrophilous species. Although Anothetus, Parvaponera, and Iridomyrmex were not collected in the present study, they are well known carnivorous/ omnivorous species, and are expected to be collected in future collections here. In summary, most ant genera collected by pig liver in this study could also be found in Hwang's study using rat carcasses, suggesting that no significant difference was found for the ant genera collected by pig liver or by rat carcass traps.

In all studies, we observed that often a single species occupied the entire pig liver, whose surface was covered with an abundance of individuals, and only a few other ant species could be found in the immediate surroundings. These "dominant" species were Carebara diversa, Pheidole noda or Technomyrmex brunneus, which were found to aggressively colonize their food resources. In the combination bait-pitfall trap studies in Taipei County, we found much higher diversity in the traps relative to the baits (Figure 3). This suggests that the combination bait-pitfall trap provides a more accurate representation of the true ant diversity than collecting off the carcass alone, which is significant given the correlation between ant diversity and microhabitat.

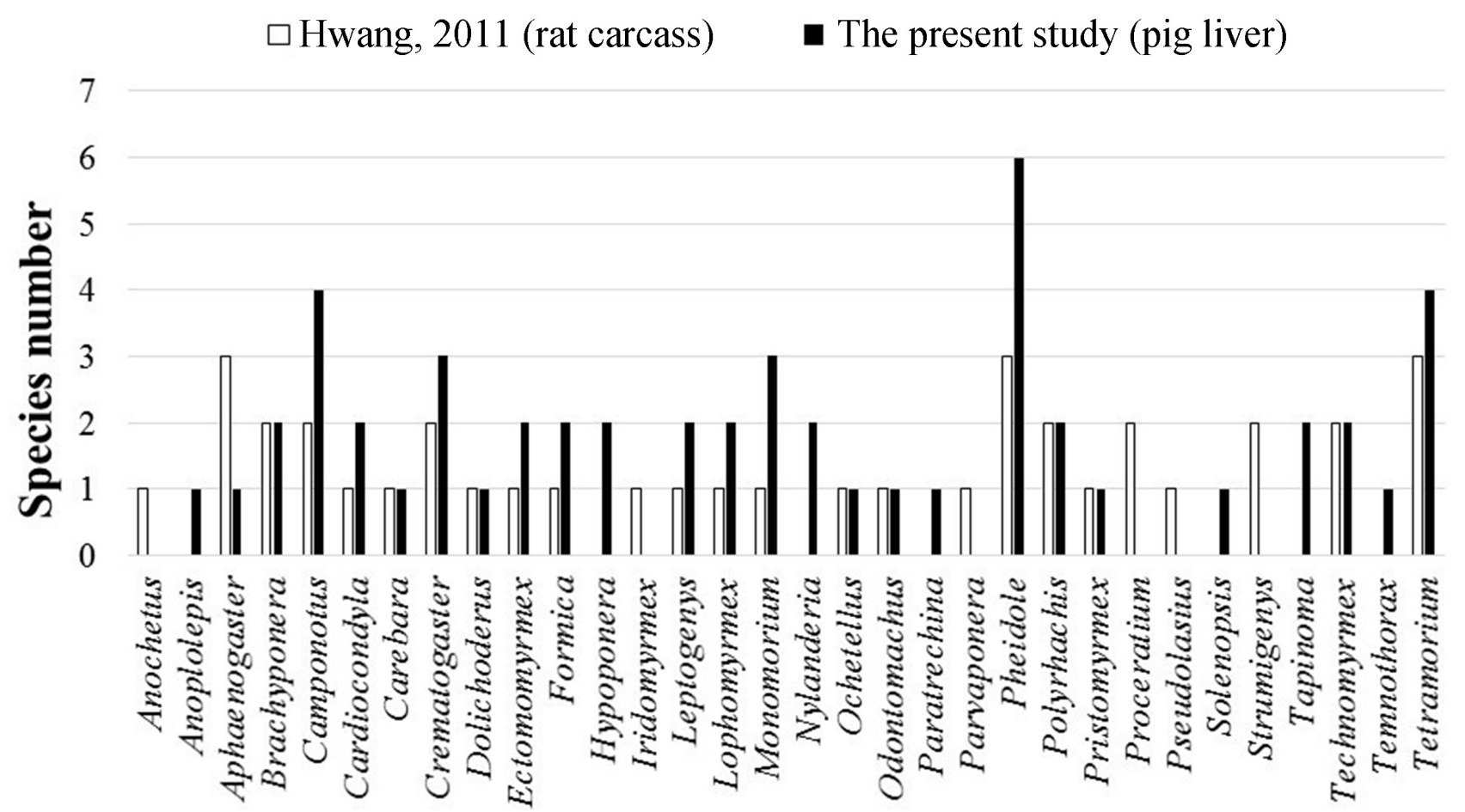

\section{Ant genera}

Fig 4. A bar diagram comparing ant genera attracted to pig liver or rat carcass baits. The white and dark bars respectively show the study of Hwang 2011 (rat carcass) and the present study (pig liver).

\section{Discussion}

This study presents the first preliminary species checklist of ants of potential forensic impact from Taiwan, and suggests ants are dominant members of the insect successional community, consistent with previous studies (Hwang, 2011; Paula et al., 2016). A total of 50 species/ morphospecies were collected in this study, which brings the number of known Taiwanese necrophilous ants to 55 species, of which 24 ant species represent new records of necrophilous ants. Taiwanese necrophilous ants are about
$19 \%(55 / 288)$ of the known Taiwanese ant species; and $46 \%(33 / 71)$ of Taiwanese ant genera (Terayama, 2009; antsmap.org, 2017). In our study, a high percentage of 5 exotic and 12 tramp species was recorded. These species are dominant in urbanized habitats (McKinney, 2008; Guénard et al., 2015), such that they are expected to colonize a body if found in its vicinity. We should note that our sampling effort across sites was not standardized and that seasons can affect insect abundance and behavior, e.g. nuptial flights; however, the data suggest that habitat type may influence ant composition. 
In most past forensic studies of ants, the researchers used carcass baits to attract arthropods, and the resulting collected ants were often a single species in large numbers fully occupying the resource (McGlynn \& Kirksey, 2000; Cerda et al., 2013). Some of these studies likely significantly under-sampled true ant diversity by only using hand collection to survey ants (Carvalho et al., 2004; Bonacci et al., 2010), promoting the use of a baited trap mixed with pitfall traps to enhance the sampling of necrophilous ants (Hwang, 2011; Castro et al., 2014; Andrade-Silva et al., 2015). In this study, we developed a simple combination bait-pitfall trap that catches a more representative sample of the true necrophilous ant diversity of a region. This design is easy to use for forensic and ecological investigations.

Among our new records of necrophilous ant species (e.g. Solenopsis geminata, Pheidole megacephala and Tapinoma melanocephalum), are species that are not only important invasive species worldwide, but also species that favor urban or non-forest habitats such as farmland (Klotz et al., 2008), instead of the forest habitats that were sampled by Hwang (2011). Moreover, we found the tropical fire ant (Solenopsis geminata) only in Pingtung County, consistent with the known distribution of the species in the south-central part of Taiwan (Terayama, 2009; antmaps.org, 2017). Several prior reports also found that ant community data can be representative of certain habitats (Andersen et al., 2002; Del et al., 2012), but recommended using many different collecting methods to collect a representative sample (e.g. Winkler bag, pitfall trap, baited trap, hand collection, etc.). Our bait-pitfall traps proved useful for detecting exotic species as well as native species, regardless of which was dominant. If the trap location was in or close to a non-forested area, then a high percentage of non-native species were detected among collected ants. Thus, the ant community on a carcass could identify where it was found or had been, especially in non-forest habitats that are strongly associated with a high percentage of exotic or tramp species (McKinney, 2008).

One problem with using ants forensically is that some ant species are aggressive and occupy the carcasses, excluding other species. Several reports noted that some ant species have particularly high biomass when collected directly from baits relative to other species (Bonacci et al., 2011; Hwang, 2011; Castro et al., 2014; Andrade-Silva et al., 2015; Paula et al., 2016; Sales et al., 2016). Similarly, we consistently observed that our combination bait-pitfall traps, though successfully catching a diverse set of species, often caught high numbers of individuals from a single species relative to the others, and that the bait itself was often fully occupied by this single species (e.g. Carebara diversa, Pheidole noda, or Technomyrmex brunneus, Figure 3). These ant species occupied the pig liver until it dried out and the fly maggots left the substrate. Which of these ant species ends up the colonizer of a given bait or body depends on the their foraging area, the location of the nest relative to the bait, the colony size of the ant, and species-specific behavior (Andersen et al., 2002).
While the diversity of ants in an area near a carcass is high, the carcass itself is usually colonized by one species. Because ants are flightless, this "occupying" species should be the one in highest abundance in that exact micro-location, for example due to a nest close-by. Such micro-location data would be best provided by ants relative to other necrophilous insects because ants are flightless, meaning a carcass cannot be colonized by ants beyond a certain distance from the hive. Other necrophilous insects (flies, beetles, wasps, moths, etc.) cannot provide micro-location data as they can fly and cover larger distances. In addition, certain ants are only found in certain habitat types (primary, secondary, and non-forested or urban areas) (Andersen et al., 2002), and their presence on a body in the wrong habitat can suggest post-mortem movement of a carcass even without pitfall trap resampling. These hypotheses should be tested in future, experimental studies.

As additional sources of data for forensic entomology investigations, ants are potentially useful for filling in the knowledge gaps that cosmopolitan blowfly data cannot, namely reconstructing the types of habitats and possibly micro-locations in which a decedent has been. On-going studies will include the recordings of the postmortem injury created by ants, and the succession of the carrion ant community in different habitats over time.

\section{Acknowledgement}

We would like to express our gratitude to Dr. Mamoru Terayama (University of Tokyo), Dr. Benoit Guénard (University of Hong Kong), Dr. Seiki Yamane (Kagoshima University Museum), and Dr. Wen-Jer Wu (NTU) for their suggestions and help, as well as anonymous referees and the editor (Dr. Evandro do Nascimento Silva). We also thank Dr. Wenbe Hwang (National University of Tainan), Mr. ShouWang Lin, and Mr. Tsung-Hsueh Wu (Insect Systematics Lab., NTU) for collecting valid specimens and information for the present study, Dr. Yzel R. Súarez (Universidade Estadual de Mato Grosso do Sul) and Mrs. Michele Castro de Paula (Universidade Federal da Grande Dourados) for their analysis information, and Dr. Sheng-Shan Lu and Ms. Yun-Yen Ye (Taiwan Forestry Research Institute) for their assistance at the insect collections of the TFRI. Lastly, our peers (Insect Systematics Lab., NTU) and other friends for providing support and assistance for the survey in Taiwan. This research was supported by Ministry of Science and Technology of Taiwan (CML, Grant No. 105-2815-C-002068-B), CML's study in Taiwan was supported by Gabinete de Apoio ao Ensino Superior, Macao SAR.

\section{References}

Andersen, A.N., Hoffmann, B.D., Müller, W.J. \& Griffiths, A.D. (2002). Using ants as bioindicators in land management: simplifying assessment of ant community responses. 
Journal of Applied Ecology, 39: 8-17. doi: 10.1046/j.13652664.2002.00704.x

Amendt, J., Krettek, R. \& Zehner, R. (2004) Forensic entomology. Naturwissenschaften, 91: 51-65. doi: 10.1007/ s00114-003-0493-5

Andrade-Silva, J., Pereira, E.K.C., Silva, O., Delabie, J.H.C. \& Rebelo, J.M.M. (2015). Ants (Hymenoptera: Formicidae) associated with pig carcasses in an urban area. Sociobiology, 62: 527-532. doi: 10.13102/sociobiology.v62i4.795

AntCat.org, (2017). Available from https://antcat.org/. (accessed date July 31st 2017).

Antmaps.org, (2017). Available from https://antmaps.org/. (accessed date July 31st 2017).

Antweb.org, (2017). Available from https://antweb.org/. (accessed date July 31st 2017).

Bonacci, T., Brandmayr, P., Greco, S., Tersaruolo, C., Vercillo, V. \& Brandmayr, T.Z. (2010). A preliminary investigation of insect succession on carrion in Calabria (southern Italy). Terrestrial Arthropods Reviews, 3: 97-110. doi: $10.1163 / 187498310 X 517123$

Bonacci, T. \& Vercillo, V. (2015). Outdoor post-mortem bite injuries by Tapinoma nigerrimum (Hymenoptera, Formicidae) on a human corpse: Case report. Journal of Forensic and Legal Medicine, 33: 5-8. doi: 10.1016/j.jflm.2015.03.005

Bonacci, T., Zetto Brandmayr, T., Brandmayr, P., Vercillo, V. \& Porcelli, F. (2011). Successional patterns of the insect fauna on a pig carcass in southern Italy and the role of Crematogaster scutellaris (Hymenoptera, Formicidae) as a carrion invader. Entomological Science, 14: 125-132. doi: 10.1111/j.1479- 8298.2010.00423.x

Campobasso, C.P., Marchetti, D., Introna, F. \& Colonna, M.F. (2009). Postmortem artifacts made by ants and the effect of ant activity on decompositional rates. American Journal of Forensic and Medical Pathology, 30: 84-87. doi: 10.1097/ PAF.0b013e318187371f

Carvalho, L.M.L., Thyssen, P.J., Goff, M.L. \& Linhares, A.X. (2004). Observations on the succession patterns of necrophagous insects on a pig carcass in an urban area of Southeastern Brazil. Anil Aggrawal's Internet Journal of Forensic Medicine and Toxicology, 5: 33-39.

Castro, C.P., Garcia, M.D., Palma, C. \& Martınez-Ibanezd, M.D. (2014). First report on sarcosaprophagous Formicidae from Portugal (Insecta: Hymenoptera). Annales de la Societé Entomologique de France, 50: 51-58. doi: 10.1080/003792 71.2014 .934037

Cerda, X., Arnan, X. \& Retana, J. (2013). Is competition a significant hallmark of ant (Hymenoptera: Formicidae) ecology? Myrmecological News, 18: 131-147.

Del Toro, I., Ribbons, R.R. \& Pelini, S.L. (2012). The little things that run the world revisited: a review of antmediated ecosystem services and disservices (Hymenoptera: Formicidae). Myrmecological News, 17: 133-146.

Goff, M.L. \& Win, B. (1997). Estimation of postmortem interval based on colony development time for Anoplolepsis longipes (Hymenoptera: Formicidae). Journal of Forensic Science, 42: 1176-1179.

Google Map. Available from https://www.google.com/maps. (accessed date July 31st 2017).

Guénard, B., Cardinal-De Casas, A. \& Dunn, R.R. (2015). High diversity in an urban habitat: are some animal assemblages resilient to long-term anthropogenic change? Urban Ecosystems, 18: 449-463. doi: 10.1007/s11252-014-0406-8

Guénard, B., Weiser, M.D. \& Dunn, R.R. (2010). Global generic richness and distribution: new maps of the world of ants with examples of their use in the context of Asia. Asian Myrmecology, 3: 21-28. doi: 10.20362/am.003004

Hölldobler, B. \& Wilson, E.O. (1990). The Ants. Cambridge, USA: Belknap Press of Harvard University Press, 732 p

Hwang, W. (2011). Environmental variables affecting community composition and carcass utilization of necrophagous ant (Hymenoptera: Formicidae) in southern and northern Taiwan. BioFormosa, 46: 21-31. doi: 10.6248/BF.2011.46(1).04

Hwang, W. \& Shiao S.F. (2012). Comparative study of species composition and seasonal activity of necrophilous beetles with emphasis on Aphodiinae and Scarabaeinae (Coleoptera: Scarabaeidae) in Subtropical and Tropical Taiwan. Formosan Entomologist, 32: 331-344. doi: 10.6661/TESFE.2012021

Lin, S.W. \& Shiao, S.F. (2013). Life history data on the fly parasitoids Aleochara nigra Kraatz and A. asiatica Kraatz (Coleoptera: Staphylinidae), and their potential application in forensic entomology. Forensic Science International, 232: 4655. doi: 10.1016/j.forsciint.2013.06.016

Lindgren, N.K., Bucheli, S.R., Archambeault, A.D. \& Bytheway, J.A. (2011). Exclusion of forensically important flies due to burying behavior by the red imported fire ant (Solenopsis invicta) in southeast Texas. Forensic Science International, 204: e1-e3. doi: 10.1016/j.forsciint.2010.05.016

McGlynn, T.P. \& Kirksey, S.E. (2000). The effects of food presentation and microhabitat upon resource monopoly in a ground-foraging ant (Hymenoptera: Formicidae) community. Revista de Biologia Tropical, 48: 629-642.

McKinney, M.L. (2008). Effects of urbanization on species richness: a review of plants and animals. Urban Ecosystems, 11: 161-176. doi: 10.1007/s11252-007-0045-4

Moura, A.O., Monteiro-Filho, E.L.D. \& de Carvalho C.J.B. (2005). Heterotrophic succession in carrion arthropod assemblages. Brazilian Archives of Biology and Technology, 48: 477-486. doi: 10.1590/S1516-89132005000300018 
National Red Imported Fire Ant Control Center. (2017). Available from http://www.fireant.tw/. (accessed date July 31st 2017).

Paula, M.C., Morishita, G.M., Cavarson, C.H., Gonçalves, C.R., Tavares, P.R., Mendonça, A., Súarez, Y.R. \& AntonialliJunior, W.F. (2016). Action of ants on vertebrate carcasses and blow flies (Calliphoridae). Journal of Medical Entomology, 53: 1283-1291. doi: 10.1093/jme/tjw119

Sales, T.A., Daemon, E. \& Lopes, J.F.S. (2016). Necrophagous or predators? The role of Pheidole radoszkowskii Mayr (Hymenoptera: Formicidae) on Rattus norvegicus (Berkenhout) carcasses (Rodentia: Muridae). Journal of Natural History, 50: 971-974. doi: 10.1080/00222933.2015.1091100

Santos W.E., Carneiro, L.T., Alves, A.C.F., Creão-Duarte A.J. \& Martins, C.F. (2014b). Stingless bees (Hymenoptera: Apidae: Meliponini) attracted to animal carcasses in the Brazilian dry forest and implications for forensic entomology. Sociobiology, 61: 490-493. doi: 10.13102/sociobiology.v61i4. 490-493

Silahuddin, S.A., Latif, B., Kurahashi, H., Walter, D.E. \& Heo, C.C. (2015). The importance of habitat in the ecology of decomposition on rabbit carcasses in Malaysia: implications in forensic entomology. Journal of Medical Entomology, 52: 9-23. doi: 10.1093/jme/tju001
Terayama, M. (2009). A synopsis of the family Formicidae of Taiwan (Insecta, Hymenoptera). Liberal Arts Bulletin, Kanto Gakuen University, 17: 81-266.

VanLaerhoven, S.L. (2008) Blind validation of postmortem interval estimates using developmental rates of blow flies. Forensic Science International, 180: 76-80. doi: 10.1016/j. forsciint.2008.07.002

Ward, P.S. (2007). Phylogeny, classification, and specieslevel taxonomy of ants (Hymenoptera: Formicidae). Zootaxa, 1668: 549-563. doi:10.11646/zootaxa.1668.1.26

Wells, J.D. (1991). Chrysomya megacephala (Diptera: Calliphoridae) Has Reached the Continental United States: Review of Its Biology, Pest Status, and Spread Around the World. Journal of Medical Entomology, 28: 471-473. doi:10.1093/jmedent/28.3.471

Wells, J.D. \& Greenberg, B. (1994). Effect of the red imported fire ant (Hymenoptera: Formicidae) and carcass type on the daily occurrence of postfeeding carrion-fly larvae (Diptera: Calliphoridae, Sarcophagidae). Journal of Medical Entomology, 31: 171-174. doi: 10.1093/jmedent/31.1.171

Yamane, S., Leong, C.M. \& Lin, C.C. (2018). Taiwanese species of the ant genus Technomyrmex (Formicidae: Dolichoderinae). Zootaxa, 4410: 35-56. doi: 10.11646/zootaxa.4410.1.2 